\title{
Evaluation of the Fermentation of Scomberomorus tritor by Express Methods: Conductimetry, pH-Metry and Refractometry
}

\author{
Mahouglo Barnabé Houessou *, Pierre Dossou-Yovo, Wilfried Zanmenou, \\ Chimène Agrippine Rodogune Yelouassi
}

Research Laboratory in Fishery Products Treatment and Conservation, Faculty of Science and Technology, University of Abomey Calavi, Abomey-Calavi, Bénin

\author{
Email address: \\ mbahyvonne88@gmail.com (M. B. Houessou) \\ ${ }^{*}$ Corresponding author
}

\section{To cite this article:}

Mahouglo Barnabé Houessou, Pierre Dossou-Yovo, Wilfried Zanmenou, Chimène Agrippine Rodogune Yelouassi. Evaluation of the Fermentation of Scomberomorus tritor by Express Methods: Conductimetry, pH-Metry and Refractometry. American Journal of Applied Chemistry. Vol. 6, No. 4, 2018, pp. 142-146. doi: 10.11648/j.ajac.20180604.12

Received: August 21, 2018; Accepted: September 4, 2018; Published: October 9, 2018

\begin{abstract}
Chance fermentation is a biochemical process of transformation and conservation during which degradation of organic molecules (proteins and lipids) occurs through the action of enzymes. Some methods often used to determine degradation products of organic molecules are expensive, slow, inefficient and even critical. But the knowledge of certain physicochemical parameters can lead us to estimate the chemical modifications that occurred during the transformation of a foodstuff. This is how conductimetry, $\mathrm{pH}$-metry and refractometry are used to make an express assessment of the fermentation of Scomberomorus tritor. The biological degradation phenomena of organic molecules being identical at the level of the hydrolyzate as whole fish, the hydrolyzate of Scomberomorus tritor is subjected to a spontaneous fermentation during 72 hours and, evolutions of the electrical conductivity, the index refraction and $\mathrm{pH}$ are recorded. The obtained results show the electrical conductivity variations between $1200 \mu \mathrm{S}$ and $8900 \mu \mathrm{S}$, the one of the $\mathrm{pH}$ between 6.8 and 6.3 and the one of the refractive index between 1.331 and 1.333 during the fermentation of Scomberomorus tritor. These variations are due to the appearance of suspended degradation products (ionized bodies), proof that there has been fermentation. The instrumental methods used allowed us to make an express assessment of the fermentation of Scomberomorus tritor. These methods are sensitive, fast, effective and do not need chemical reagents.
\end{abstract}

Keywords: Chance Fermentation, Conductimetry, pH-metry, Refractometry, Scomberomorus Tritor

\section{Introduction}

In food processing, micro-organisms may have the following effects: aromatization, texture alteration and influence on external appearance, improvement of nutritional characteristics, stabilization and conservation. Among these effects, some result from a fermentative metabolic action. The others are from the production of exo or ectocellular enzymes, bioconversion or the elimination of certain molecules from the product [1]. Fermentation, a method of transformation and preservation, leads to a degradation of organic molecules such as proteins and lipids by improving the nutritional quality of foods. Fermentation enhances the nutrient content of foods through the biosynthesis of vitamins, essential amino acids and proteins, improving protein and fiber digestibility, enhancing the bioavailability of micronutrients and reducing antinutritional factors [2-4]. The content of foods and food ingredients is essential not only to ensure the quality and safety of foods, but also to facilitate trade. The lack of reliable quantitative methods leads directly to the alteration of protein-rich foods with melamine and non-protein compounds in 2007 to $2008[5,6]$. This adulteration has resulted in injury and death of infants in the case of adulterated milk preparations and the injury and 
death of pets in the case of adulterated pet foods [7]. The two primary chemical methods of protein measurement (the Kjeldahl method and the Dumas combustion method) based on the determination of total nitrogen as a marker for estimating protein content [8] are used in the food industry and the labs of food regulation to perform total protein measurements [9]. The lack of analytical selectivity for contents such as dietary protein and the potential for adulteration with nonprotein nitrogen has been recognized since the mid-20th century [10]. The economic and public health implications of measuring food content show the need for analytical performance. Current methods based on, for example, total nitrogen do not reach the level of selectivity and specificity required for total protein measurement; therefore alternative analytical methods with improved selectivity need to be developed and adopted. These new methods must also maintain unusually high levels of accuracy and precision required for ingredient and food analysis $[11,12]$. The intrinsic limitations of these traditional methods of food analysis dictate a new approach to analysis, if only to appreciate the state of the food environment. Especially, in terms of fermentation, the urgency to appreciate the appearance or not of organic decomposition products.

The objective of this work is to make an express assessment of the fermentation by certain physical methods (instrumental) for the determination of the presence of degraded products of organic molecules such as proteins and lipids. To achieve this, we made a kinetic study of the fermentation of Scomberomorus tritor based on certain physico-chemical parameters such as temperature, $\mathrm{pH}$, electrical conductivity and refractive index.

\section{Material and Methods}

\subsection{Biological Material}

For this study, we used Scomberomorus tritor hydrolyzate. Scomberomorus tritor is known for its good nutrient composition and adaptation to processing for preservation. Hydrolysates have the same advantages as raw materials of animal origin, for aquaculture without having the many disadvantages [13]. The biochemical phenomena of organic molecules degradation are therefore as identical to the levels of the hydrolyzate as whole fish.

\subsection{Laboratory Equipment}

In addition to glassware, an ATC $\mathrm{pH}$-meter, a thermometer, a HANNA digital conductivity meter and an eclipse refractometer are used for measurements.

\subsection{Method for Obtaining the Hydrolyzate}

The hydrolyzate is obtained from the crushed fish. The Figure 1 below describes the process of obtaining.

\subsection{Expression of Fermentation Methods}

In nineteen bowls we respectively introduce $100 \mathrm{~mL}$ of the fish hydrolyzate into each. The bowls are hermetically sealed and placed in an anaerobic environment; and the fermentation began.

Measurements of electrical conductivity, $\mathrm{pH}$, refractive index and temperature are made at 4 hour intervals for 72 hours.

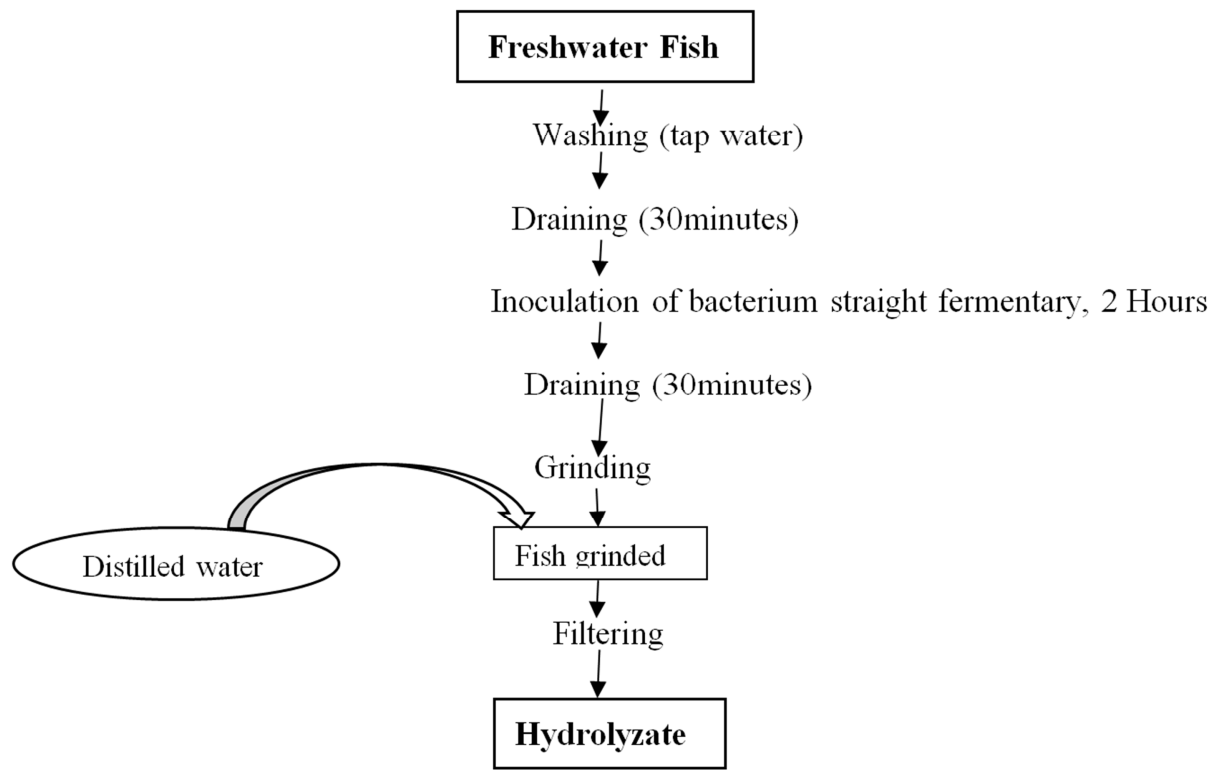

Figure 1. Production of the hydrolysate.

\section{Results and Discussion}

Chance fermentation is a degradation of organic molecules (proteins, lipids ...) under the effect of indigenous enzymes. The analyzes carried out allowed us to have the kinetics of electrical conductivity, $\mathrm{pH}$ and the refractive index; then to determine the influence of time and temperature; next to make the correlation between time and the different physicochemical parameters taken during these analyzes. 


\subsection{Evolution of the Electrical Conductivity}

The electrical conductivity of a solid or liquid material, provides us with information on its capacity or ability to conduct an energy underpinned by ionized particles. The electrical conductivity of a sample gives a value which is the sum of the independent contributions of all the ions present in the solution [14]. The degradation of the organic molecules of a body gives ionized bodies. Figure 2 shows the kinetics of the electrical conductivity.

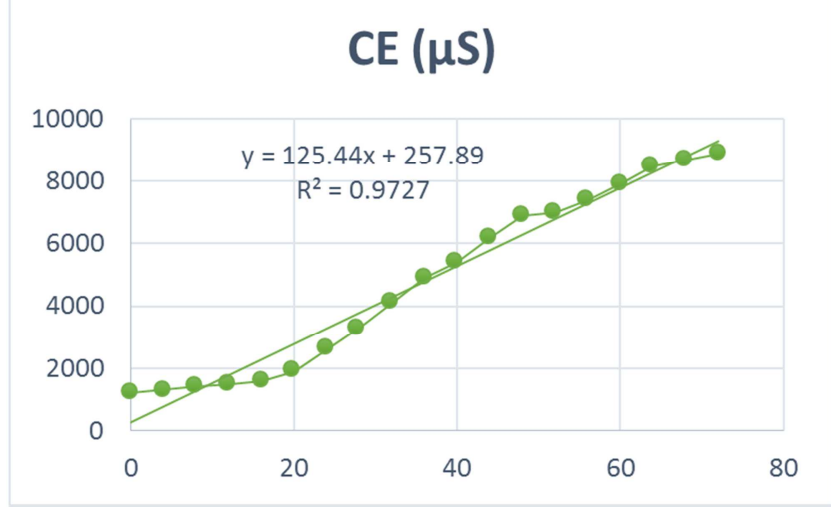

Figure 2. Kinetics of electrical conductivity.

This kinetics shows an increase in electrical conductivity over time during fermentation. This increase in electrical conductivity provides information on the degradation of organic molecules leading to a multiplication of particles in suspension, that is to say ionized bodies; this shows that chemical changes would have occurred during the fermentation process. These results confirm the work of Pearson (1962) [15], which states that during fermentation, enzymatic degradation of nucleotides and nucleosides occurs, resulting in the formation of inosine, hypoxantine, ribose, and the like formation of dimethylamine, then decomposition of proteins with subsequent formation of ammonia, indole, hydrogen sulphide.

The electrical conductivity of a solution is proportional to the concentration of the latter. An increase in electrical conductivity therefore means an increase in the concentration of ionized materials. Conductimetry can therefore be a scientific analytical instrument of the fermentation based on the search for quantitative information in representative samples of targeted systems. The main disadvantage of the method is that the conductimetric measurements are nonspecific that is to say that different ions can not be measured separately. This requires working with pure compounds. For samples containing several ions, the knowledge of the $\mathrm{pH}$ can lead to identify the nature of these ions.

\section{2. pH Evolution}

Figure 3 shows the evolution of the $\mathrm{pH}$ during the fermentation of Scomberomorus tritor.

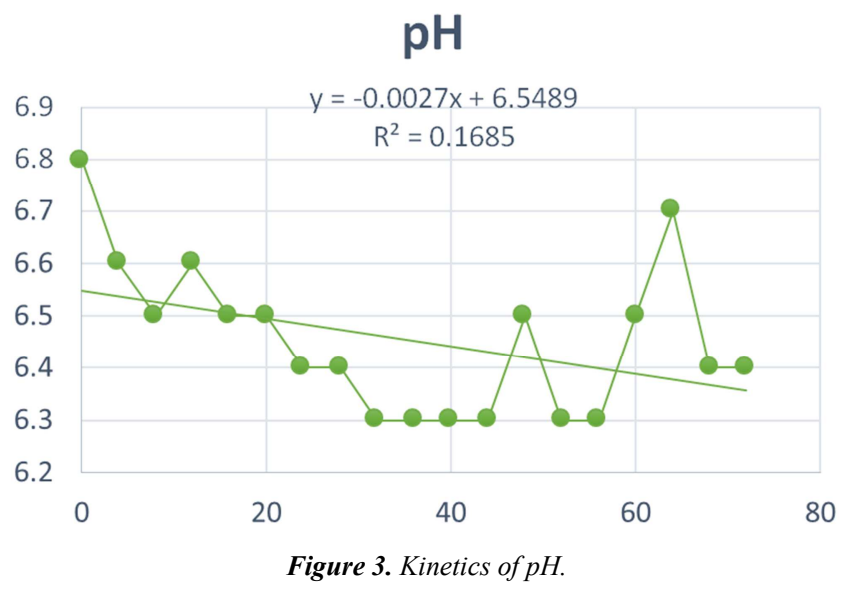

This kinetics exhibits $\mathrm{pH}$ variations between the extremes 6.8 and 6.3. This is in line with the work of GREGOIRE C. (2007) [16] which estimates that during enzymatic hydrolysis the maximum $\mathrm{pH}$ is 6.9 and the minimum is 6.2. The hydrolysis of the peptide bonds will therefore generate the release of $\mathrm{H}^{+}$protons. This release of $\mathrm{H}^{+}$protons will induce acidification of the medium. This principle is valid for hydrolyses taking place at a $\mathrm{pH}$ greater than 6.5 , so that the degree of dissociation of the $\mathrm{R}^{-\mathrm{NH}_{3}}{ }^{+}$ions is sufficient [17].

A linear trend of this kinetics shows a lowering of $\mathrm{pH}$ over time. The lowering of the $\mathrm{pH}$ would be due to the accumulation of fatty acids resulting from the degradation of lipids. The degradation of the proteins gives amino acids which, under the effect of the increase or the variation of the temperature, can undergo decarboxylation reactions giving a release of the carbon dioxide and amines transforming themselves into weak acids in medium aqueous. The lowering of $\mathrm{pH}$ is probably due to the accumulation of acid, particularly lactic acid, produced by lactic acid bacteria [18]. Daily chemical and biochemical processes are controlled by $\mathrm{pH}$ measurements. This is probably the most measured chemical parameter that most people hear or speak. The fact that $\mathrm{pH}$ meters are widely available at a relatively low cost and that the measurements are fairly simple, even for those who do not have professional training, has led to the misconception that everything is known and clear about the $\mathrm{pH}$. In fact, beyond the simple process of measuring $\mathrm{pH}[19$, 20], there is a misunderstanding of the concept, the basis of its derivation and the limits of its applicability. Despite the various basic disadvantages, $\mathrm{pH}$ measurements are popular, easy, sensitive, reliable, important and useful, and will continue to be made. Knowledge of the $\mathrm{pH}$ thus makes it possible to make a qualitative analysis of the elements contained in a sample.

\subsection{Evolution of the Refractive Index}

The degradation of organic macromolecules (proteins and lipids) during fermentation leads to embrittlement of the fermentation medium. This increase in the density of the medium can favor the reflection of light rays in the medium. Figure 4 gives the kinetics of the refractive index during the fermentation of Scomberomorus tritor. 


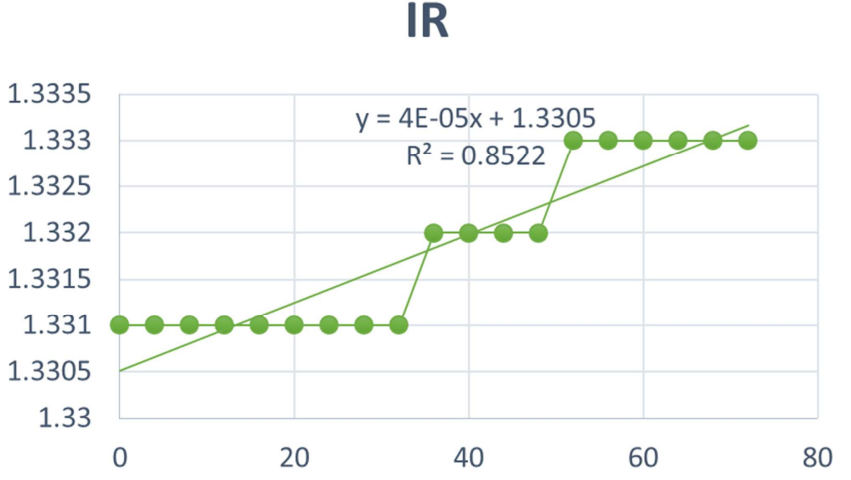

Figure 4. Kinetics of the refractive index.

This kinetics shows an evolution of the refractive index over time. This increase in the refractive index indicates that there are more and more breaks in the molecular bonds over time. It is noted that this kinetics of the refractive index has stabilization phases. These stabilization phases are due to the electrostatic effects because after cutting, the medium being aqueous, it forms ionic bonds, hydrogen, maintaining constant the density of the medium in a short time. Under the influence of temperature and $\mathrm{pH}$, the density decreases and the refractive index increases.

The refractive index is a physico-chemical parameter that allows not only to determine the state of a mixture, but also to identify a chemical species and to control its purity [2123]. It is therefore a reliable, useful and easy way in the quantitative and qualitative analysis of the elements of a sample (anonymous).

\subsection{Statistical Analyses}

They are carried out using the Minitab 18 software. The table 1 below shows the correlations of Pearson and the significant differences between the physicochemical parameters evaluated during the fermentation of Scomberomorus tritor.

Table 1. Correlation of Pearson and P-value.

\begin{tabular}{lllll}
\hline & Temps $(\mathbf{H})$ & IR & $\boldsymbol{\Theta}\left({ }^{\circ} \mathbf{C}\right)$ & $\mathbf{C E}(\boldsymbol{\mu} \mathbf{S})$ \\
\hline \multirow{2}{*}{$\mathrm{R}$} & 0.923 & & & \\
& 0.000 & & & \\
$\Theta\left({ }^{\circ} \mathrm{C}\right)$ & 0.311 & 0.091 & & \\
& 0.195 & 0.711 & & \\
$\mathrm{CE}(\mu \mathrm{S})$ & 0.986 & 0.947 & 0.213 & \\
& 0.000 & 0.000 & 0.382 & \\
$\mathrm{pH}$ & -0.411 & -0.271 & -0.777 & -0.359 \\
& 0.081 & 0.262 & 0.000 & 0.131 \\
\hline
\end{tabular}

An analysis of this table indicates strong correlations between, on the one hand, the time and refractive index and then the time of the electrical conductivity, and on the other hand, between the refractive index and the electrical conductivity. These strong correlations are explained by the fact that over time, during fermentation, the medium is increasingly loaded with ionized particles following the degradation of organic molecules thus decreasing the density. It should be noted that there is no significant difference ( $p$ $<0.05$ ) between the time, the electrical conductivity and the refractive index. This confirms once again the simultaneous evolutions observed between these parameters.

No correlation is observed between the $\mathrm{pH}$, the temperature and the other physico-chemical parameters that are the subject of this study. Only between the $\mathrm{pH}$ and the temperature that there is no a significant difference thus checking the expenditure of the $\mathrm{pH}$ at the temperature.

\section{Conclusion}

The instrumental methods (conductimetry, pH-metry and refractometry) are quite reliable, sensitive and simple to carry out the qualitative and sometimes quantitative analysis of the fermentation degradation products of Scomberomorus tritor. They are economical and save time.

\section{References}

[1] BRANGER, A. (2004). "Fabrication de produits alimentaires par fermentation: les ferments." Techniques de l'ingénieur. Agroalimentaire 2(F3500): F3500. 3501-F3500. 3516.

[2] Jeantet, R., et al. (2008). Sciences des Aliments 1-Stabilisation biologique et physico-chimique, Tec \& Doc Lavoisier.

[3] Kouakou, A. C., et al. (2012). "Molecular bacterial characterization and free amino acids composition in Ivorian traditional fermented fish produced by two methods." Fisheries science 78(5): 1125-1136.

[4] Zeng, X., et al. (2013). "Effect of autochthonous starter cultures on microbiological and physico-chemical characteristics of Suan yu, a traditional Chinese low salt fermented fish." Food control 33(2): 344-351.

[5] Ingelfinger, J. R. (2008). "Melamine and the global implications of food contamination." New England Journal of Medicine 359(26): 2745-2748.

[6] Urh JJ. 2008. Protein testing enters the 21st century: innovative protein analyzer not affected by melamine. Am Lab 40(18):18-19.

[7] Moore, J. C., et al. (2010). "Total protein methods and their potential utility to reduce the risk of food protein adulteration." Comprehensive Reviews in Food Science and Food Safety 9(4): 330-357.

[8] Owusu-Apenten, R. (2002). Food protein analysis: quantitative effects on processing, CRC Press.

[9] Krotz, L., et al. (2008). "Protein determination in cereals and seeds." Food Quality 15(4): 37-39.

[10] Huss W. (1959). Microscopic and enzymic for detection of adulteration of feed urea. Landwirt Forsch 12: 171-7

[11] Barbano, D. and J. Lynch (2006). "Major advances in testing of dairy products: Milk component and dairy product attribute testing." Journal of dairy science 89(4): 1189-1194.

[12] Sun, D.-W. (2008). Modern techniques for food authentication, Academic Press.

[13] Leclercq, B. and M. Larbier (1992). Nutrition et alimentation des volailles, Quae. 
[14] Szabadváry, F. (2016). History of Analytical Chemistry: International Series of Monographs in Analytical Chemistry, Elsevier.

[15] Pearson, W. N. (1962). "Biochemical appraisal of nutritional status in man." The American journal of clinical nutrition 11(5): 462-476.

[16] GREGOIRE, C. (2007). Contribution à l'étude de la valorisation des protéines d'hydrolysats obtenues par hydrolyse enzymatique des co-produits (squelette) de la sole tropicale: Cynoglossus senegalensis au Sénégal, UNIVERSITE CHEIKH ANTA DIOP DE DAKAR.

[17] Ravallec, R. (2000). Valorisation d'hydrolysats d'origine marine: optimisation de la concentration en peptides apparentés aux facteurs de croissance et aux agents sécrétagogues: essais in vitro et in vivo, Brest.

[18] Vessman J, Stefan RI, Van Staden JF, Danzer K, Lindner W, Burns DT, Fajgelj A, Muller H. (2001). Selectivity in analytical chemistry (IUPAC Recommendations 2001). Pure Appl Chem 73(8):1381-6.
[19] Herbert, N. (1973). In Ion-selective Microelectrode,(ed: Berman, HJ and Herbert, NC) 23-41, Plenum Press New York.

[20] Landry, J. and S. Delhaye (1996). "A simple and rapid procedure for hydrolyzing minute amounts of proteins with alkali." Analytical biochemistry 243(1): 191-194.

[21] Foster, A. (1989). "Alternative method for analysis of total protein using the nitrogen determinator." Journal of the American Society of Brewing Chemists 47(2): 42-43.

[22] Goldberg, H. D., et al. (1994). "Screen printing: a technology for the batch fabrication of integrated chemical-sensor arrays." Sensors and Actuators B: Chemical 21(3): 171-183.

[23] Ellis C, Hite D, Van Egmond H. (1998). Development of methods to test all food matrixes unrealistic, says OMB. Inside Laboratory Management 1(8):33-35. 